\title{
MEDIAÇÃO - UM INSTRUMENTO DE PACIFICAÇÃO SOCIAL: EDUCAR PARA A PAZ
}

\section{MEDIATION - AN INSTRUMENT OF SOCIAL PACIFICATION: TO EDUCATION FOR THE PEACE}

Resumo: A partir da constatação da situação atual do Judiciário, da tendência à desjudiciarização dos meios de solução de conflitos e das características peculiaridades da mediação, discute a inclusão desse novos mecanismos no nosso sistema e apresenta propostas para sua contextualização e de mudanças de paradigma para sua maior abrangência e efetividade, como fator de indução para a cidadania e a paz.

Palavras-chave: Mediação. Cidadania. Pacificação de conflitos.

Abstract: Starting from the verification of the current situation of the Judiciary, of the tendency to the no legalization of the medium of solution of conflicts and of the characteristic peculiarities of the mediation, the inclusion of that new mechanisms discusses in our system and it presents proposed for its insertation and of paradigm changes for its largest inclusion and effectiveness, as induction factor for the citizenship and the peace.

Keywords: Mediation. citizenship. Pacification of conflicts.

"Nosso desafio atual é transformar a própria cultura do conflito dentro da nossa família, do nosso local de trabalho, da nossa comunidade e do nosso mundo.

É criar uma cultura na qual até as divergências mais graves sejam resolvidas, não na base da força e da coerção, mas do interesse mútuo e da coexistência.

Nosso desafio não é eliminar as diferenças, mas tornar o mundo mais seguro para elas.” (URY, 2000, p. 8).

Docente titular do programa de Mestrado em Direito Negocial da Universidade Estadual de Londrina. Doutora em direito pela PUC/SP. 


\section{INTRODUÇÃO - A IMPORTÂNCIA DA MEDIAÇÃO NA ATUALIDADE}

Nos dia atuais busca-se a simplificação dos procedimentos, a redução de despesas e de tempo e a diversificação de formas de acesso à justiça que permitam uma solução dos litígios que possibilite uma paz duradoura, principalmente pela constatação da incapacidade do estado de atender a multiplicação das demandas e de suprir as necessidades da população. Nesse sentido, os meios alternativos de solução de controvérsias são hoje um caminho indispensável na busca por esta simplificação da justiça, que a torne oportuna e que permita a aproximação dos cidadãos desta e esta daqueles, desobstruindo os tribunais.

Estes mecanismos têm a aptidão de permitir a participação efetiva das partes e de estimular a comunicação e a composição justa dos problemas, na medida de justiça apresentada pelos envolvidos, através de procedimentos orientados pela simplicidade, adequação, informalidade e economia processual, tendo apresentado resultados positivos em experiências pelo mundo e em programas e projetos pelo Brasil, dados estes que embasam a conveniência do desenvolvimento de sua utilização. ${ }^{1}$

Dentre estes institutos, a mediação, em especial, é um mecanismo diferente do modelo tradicional de justiça, cuja tendência é de enxergar o mundo por uma ótica jurídica, imutável, condicionada a priorização de peças processuais, pela qual a sentença traz a finalidade maior da jurisdição, pacificação social, formatado pela litigiosidade e confirmador de uma visão adversarial de solução que gera mais conflitos - litigiosidade residual contida-, pois, solucionar conflitos vai muito além da prolação da sentença, depende de uma visão integral da questão e dos envolvidos e da possibilidade de intervenção social efetiva para se chegar à pacificação social. Ela tem a possibilidade de alcançar os objetivos pretendidos, dentro ${ }^{2}$ e fora do Judiciário ${ }^{3}$, além de poder ir além, através da

${ }^{1}$ Relatório nos termos do artigo $65^{\circ}$, no. 3 da lei 78/2001, de 13 de julho à apresentar à Assembléia da República, pelo Conselho de Acompanhamento dos Julgados de Paz, Presidência conselheiro J.O.Cardona Ferreira. (Disponível em: 〈http://www.oa.pt/>. Acesso em: 24 fev. 2004).

${ }^{3}$ Kazuo Watanabe (2004, p. 50) expressa: “[...] é muito mais importante a atuação do juiz, do profissional do Direito na pacificação da sociedade do que na solução do conflito. É mais relevante para o juiz um acordo amigável, mediante uma conciliação das partes, do que uma sentença brilhante proferida e que venha a ser confirmada pelos tribunais superiores. Os tribunais superiores precisam começar a aferir o mérito do juiz por uma atitude diferente diante de sua função judicante, que não consiste 
Mediação - um instrumento de pacificação social: educar para a paz

busca de consensos e da indução de posturas não adversariais, tem a capacidade de possibilitar a resolução de conflitos cotidianos concretos, que incomodam a vida das pessoas e, com isto, prevenir a instalação efetiva e o aprofundamento dos mesmos, aproximando, ainda mais, a justiça e o direito da sociedade.

Mas, apesar de decantadas suas vantagens por inúmeros estudiosos, para falarmos da efetividade de sua utilização, devemos avaliar como se encontra a percepção da sociedade dos modelos e padrões vigentes; quais as possibilidades de aceitação desta técnica de pacificação e inclusão social e de solução e pacificação de conflitos; e quais as modificações necessárias, se necessárias, para sua implantação.

\section{O DIREITO E A TRANSFORMAÇÃO DA SOCIEDADE}

A primeira pergunta que fazemos é: Será que se resolvem problemas com leis? Será que as leis podem alterar quadros sociais? Entendemos que “...o centro da gravidade do desenvolvimento do direito não se encontra na legislação, nem na ciência jurídica, mas sim na própria sociedade [...] se a vida social muda, sob o influxo da nova civilização...” (BARRETO, 1955, p. 71) o direito, como fenômeno eminentemente social, não pode ficar estático. Assim, o direito, como sistema adaptativo que é, deve ajustar seus elementos, relações, organização, desempenhos, objetivos e formas de administração em função da evolução da sociedade. Ou seja, as alterações devem ocorrer primeiro na sociedade.

Apesar de presentes em nosso ordenamento jurídico, esses mecanismos ainda não estão integrados à nossa cultura, então, para utilizarmos a mediação como forma de acesso à justiça e pacificação social sua implantação no sistema tem que ir muito além da questão da estrutura oficial de conflitos. Pois, "Nenhuma 'revolução' puramente processual é suscetível, por si só, de produzir, na estrutura jurídico-social, modificação definitiva”. (BARBOSA MOREIRA, 2000, p. 142). A aceitação de sua utilização como fomentador da paz social passa pela necessidade da formação de uma cultura de paz que não faz parte de nossa

apenas em proferir sentença, dizendo qual a forma correta, se é preto ou branco, se é certo ou errado, solucionando apenas o conflito e não trabalhando para a pacificação da sociedade. É importante haver uma mudança de mentalidade dos profissionais do direito e da própria sociedade."

${ }^{3}$ Roberto Portugal Bacellar ensina que a "mediação se insere em um modelo consensual (ganha/ganha) para as controvérsias. [...] As técnicas de mediação buscam solução pacífica para as controvérsias e podem ser aplicadas dentro e fora do Poder Judiciário." (1999, p. 122). 
sociedade $e^{4}$ cuja estrutura ou modelo está assentada no paradigma adversarial judiciário que se baseia na aplicação coativa da legislação vigente às questões passadas e não na resolução autônoma, cooperativa e responsável dos conflitos voltada para as relações interpessoais e para a continuidade e o futuro das mesmas.

É necessário, então, proporcionar a possibilidade de reestruturação das certezas e percepções da sociedade para que, juntamente com os modelos atuais que se preocupam em resolver para o passado, possamos implantar um novo padrão que tem como premissa resolver para o futuro. Podemos dizer que o maior desafio é aprendermos a viver harmoniosamente, a resolver conflitos de forma colaborativa, capacidade da qual dependem nossos relacionamentos, pois a humanidade, de um modo geral, se habituou a buscar soluções através da força, pelo uso efetivo ou pela sua ameaça pondo fim aos conflitos, mas não os solucionando e nem sempre proporcionando a paz efetivamente. (URY, 2000, p. 15-22). Os meios alternativos de solução de conflitos, vistos pela ótica da convivência, atuam como um estímulo ao consenso, como geradores de sociabilidade e como tal transformadores da administração do litígio numa oportunidade de exercício de cidadania, no sentido de administração da Justiça e de assunção de responsabilidade em relação à paz na sociedade. ${ }^{5}$

Apesar do mito de vivermos em uma sociedade diferente, sem discriminação e pacífica, verificamos que a chamada Lei de Gérson (levar vantagem em tudo) predomina, o respeito ao público e o senso de coletividade não faz parte da consciência da maioria, podemos perceber prédios públicos depredados, pichados, livros furtados de bibliotecas, sonegação fiscal, desvio do dinheiro público,

${ }^{4}$ José Carlos de Mello Dias exemplifica essa realidade: "Na reclamação trabalhista, por exemplo, há conciliação desde 1943. O juiz gasta cinco minutos para fazer uma tentativa de conciliação; daí o seu fracasso. Os objetivos da mediação são facilitar o acesso a um procedimento mais efetivo, proporcionar mais tutela e menos custo, diversificar formas de resolução de conflitos, 'desjusticializar' o sistema, instaurar a cultura do diálogo, bem como abandonar a cultura do litígio. É preciso nos convencermos de que não é necessário que a cada ofensa corresponda um litígio, e, sim, que disponhamos de meios suficientemente ágeis e capazes de resolver a controvérsia, sem que haja a necessidade da figura imperativa do juiz, da figura impositiva do Estado. [...]Propõe-se substituir o sistema adverso vigente por um sistema de negociação, de intermediação, [...]. A mediação não visa apenas a diminuir ou descong estionar a carga da nossa Justiça [...].” (DIAS, 2004, p. 55-6).

${ }^{5}$ Ver MATIAS, Maria Judite. Julgados de Paz versos centros de arbitragem estruturas de mediação de consumo: conflito ou convergência? Disponível em: <http://www.oa.pt/ >. Acesso em: 23 fev. 2003. 
Mediação - um instrumento de pacificação social: educar para a paz

trânsito caótico pelo desrespeito às leis, violência entre alunos, alunos e professores, vizinhos, pais e filhos. Onde está a convivência pacífica?

O certo é que quando há a acumulação de agressividade com a ausência de mecanismos de compreensão e assimilação de suas causas, a tendência é chegarmos aonde chegamos, à violência. E, quando pensamos em paz como conseqüência da ação contra a violência, vemos que, para chegarmos a ela, temos que passar pelas questões sócio-econômica e de proteção aos direitos humanos - desculpa para a inação de muitos. Porém, cruzar os braços diante das disparidades sociais alegando impossibilidade de se atingir o objetivo também não parece solução. Acreditamos que a atuação preventiva é menos onerosa, traz menos seqüelas e mais resultados ${ }^{6}$ - é melhor prevenir as doenças do que remediar os doentes.

\section{UMA PROPOSTA DE TRANSFORMAÇÃO DA ORGANIZAÇÃO SOCIAL E CONTEXTUALIZAÇÃO DO SISTEMA JURÍDICO BRASILEIRO}

Apesar de perdurar em nossos dias a noção de que os conflitos e a violência nas sociedades são inerentes ao homem, desde os primórdios da vida humana até o início das civilizações, não há sinais de que este utilizasse meio violento para resolvê-los, ao que tudo indica, com base em dados antropológicos, o uso da força e as grandes controvérsias surgiram com o fenômeno da civilização, o que denota ser uma questão cultural e não da natureza humana. (URY, 2000, p. 45 et seq.).

Portanto, podemos afirmar que a civilização trouxe inúmeros avanços mas também criou uma cultura adversarial, e para alcançarmos uma sociedade pacífica, temos que estabelecer uma cultura para a paz. Aliás, para se alcançar a paz, por mais utópica que pareça, é necessário uma formação para a paz, pois, democracia, direitos humanos, igualdade, pacificação social se alcançam através da assimilação cultural de um povo de conceitos e ações, transformações a serem alcançadas com uma educação para a paz, que nos permita aprender a lidar de maneira construtiva com nossos conflitos.

Nesse intuito, além das atuações que vêm sendo desenvolvidas na sociedade para implementar essas concepções de paz, as mutações legislativas, nacionais e internacionais, têm demonstrado, de forma evidente, a importância do direito

${ }^{6}$ Lília Maia de Morais Sales defende serem "oferecidos à sociedade instrumentos de conscientização de direitos e deveres, de participação social e política, de solução ativa e pacífica de conflitos para que haja uma transformação cultural - da inércia social, para a participação ativa dos indivíduos nas decisões individuais e coletivas, da exclusão para a inclusão social.” (SALES, 2003, p. 130-1). 
nessa mudança de mentalidade e da prática social, como motor de uma cultura colaborativa. Ou seja, sabemos que a mudança de estrutura social e de parâmetros para a construção da cidadania passa pela transformação da sociedade e pela assimilação de novas estruturas mas, que técnicas procedimentais de solução de conflitos só poderão sobreviver se tiverem amparo no ordenamento jurídico, assim como o aumento de sua importância prática não ocorre com a afirmação de sua necessidade, mas com a existência clara de incentivos e vantagens para sua utilização.

Evidente a importância do estado, o grande pacificador e gestor dos interesses da sociedade, mas que deve atuar de forma mais efetiva, como fomentador e condutor da implantação deste paradigma, não somente no tocante à modernização do judiciário, mas como modernizador da justiça, mais próxima do indivíduo e transformadora da sociedade, e na contextualização do sistema para se alcançar soluções jurídicas alternativas de forma privada, em especial, a mediação.

\subsection{Fundamento}

O que se propõe não é simplesmente a alteração legislativa, mas uma adaptação da organização social através da implantação de uma política pública voltada à solução e prevenção de conflitos e para inclusão e pacificação social, para a educação e formação de uma cultura de paz, pois os movimentos sociais estão ligados à educação do povo, amarrando, em um grande sistema, os aspectos da vida humana, construindo assim um ambiente para o desenvolvimento da participação política, cívica e, por consequente, para a construção da paz. ${ }^{7}$

A mediação, nesse sentido, além de atuar na busca destes objetivos, é um instrumento importante, pois possibilita a participação individual que resulta em cidadania. Para sua utilização, temos que procurar entender o mundo em que vivemos e nos adaptar às transformações, conformando nosso direito positivo e, indo além, embasando o caráter inovador destes mecanismos de solução de controvérsias de forma a promover, incentivar e divulgar sua maior utilização de maneira segura e que proporcione maior acesso à justiça e não uma forma de se postergá-la ${ }^{8}$. A alteração da atual atuação estatal e a assunção de uma postura

\footnotetext{
7 "Ensina-se paz quando se ensina a resolver a prevenir os conflitos de maneira amigável, quando se restaura o diálogo, quando se oferece possibilidades de conscientização de direitos e de responsabilidade social, quando se substitui a competição pela cooperação, o individual egoísta pelo coletivo solidário.” (SALES, 2004, p. 167).
} 
Mediação - um instrumento de pacificação social: educar para a paz

ativa, no sentido de estruturar a utilização deste mecanismo pela sociedade, é um caminho possível para a reversão desse quadro. ${ }^{9}$

Pelo que, não podemos pensar a mediação somente do ponto de vista processual, mas em um ambiente muito mais amplo, de política a ser desenvolvida em todo o estado com sua implantação e com a formação de mediadores em todos os níveis sociais e de conflitos. Pois, somente a positivação de normas, constitucionais ou infraconstitucionais, não é suficiente para modificar um quadro social alicerçado em uma cultura adversarial que concebe a negociação como forma de perda de status e de poder.

É necessário não apenas permitir e facilitar a mediação, mas disseminar o mecanismo no comportamento e na mentalidade coletiva, moldada pela história, tradição e costumes, refazendo ou reescrevendo a história, a tradição e o costume, através da inclusão de transformações sociais de ordem cultural, psicológica e pedagógica que alterem a consciência coletiva, minando a concepção adversarial e criando uma consciência cooperativa, de responsabilidade e de participação da sociedade civil na administração de conflitos e na condução de seus próprios desígnios.

Além de disseminar a solução alternativa de conflitos e estimular a pacificação social, uma política voltada para a implantação deste mecanismo combateria os efeitos da violência estrutural ${ }^{10}$ e da cultura de paternalismo estatal, este último fruto da forma de nossa colonização ${ }^{11}$ e dos períodos ditatoriais de nossa história, que determinam a tendência de se ver o estado como o grande provedor e como único solucionador possível e imparcial dos conflitos e dos problemas ${ }^{12}$.

${ }^{8}$ Kazuo Watanabe revela semelhante preocupação: "Convenço-me, cada vez mais, que sem pensarmos na organização adequada da sociedade, mas apenas em aprimorar processos, não estaremos resolvendo o problema de tratamento adequado dos conflitos que ocorrem na sociedade." (WATANABE, 2004, p. 45).

9 A atuação estatal nesse sentido viria a atender às conclusões da reunião de peritos da Comissão de Segurança Hemisférica, de 05/10/1990, que recomenda elaborar um projeto de programa sobre educação para a paz no hemisfério, abrangendo três áreas: a educação para a solução pacífica de conflitos; a educação para a promoção dos valores e práticas democráticas; e a educação para a promoção da paz entre Estados.

${ }^{10}$ A violência, arraigada e presente na estrutura social, acarreta uma anestesia social que parece confortar a sociedade em relação aos problemas. (BRITTO, 2004).

11 "A época da colonização, não interessava, definitivamente a Metrópole que seus jurisdicionados tivessem justiça que lhes protegesse os interesses, [...]. O mesmo sentimento prolongou-se após o ato de 1822, chamado com muita boa vontade de independência, [...]. A república pouco inovou, tendo sido proclamada de cima para 
Talvez a escusa ou a dificuldade para o desenvolvimento desta política, e um dos maiores problemas, seja a questão econômica, a disponibilidade de recursos, diminutos diante das necessidades sociais existentes em um estado com tantas desigualdades sociais e miserabilidade, contudo, justifica-se a despesa pelo efeito transformador a ser alcançado, uma vez que estes devem ser utilizados em prol do interesse de todos, do bem-estar e da paz coletiva.

O estabelecimento de uma política nacional de inclusão e pacificação social e acesso à justiça através da mediação deve traçar a espinha dorsal de sua implantação com o estabelecimento de diretrizes e mecanismos. Essa espinha dorsal teria a função de sustentar a existência, viabilidade e eficácia da mediação no sistema brasileiro, criando um "microssistema" que atenda às peculiaridades de seus objetivos, a saber, prevenção e pacificação de conflitos e inclusão e pacificação social.

\subsection{Fundamentos e objetivos}

O objetivo geral da política estatal deve ser o de promover o bem-comum, a inclusão social, a paz social e um acesso à justiça mais próximo do indivíduo através do uso da mediação, tendo ainda a capacidade de atingir uma série de objetivos específicos.

Dentre estes temos uma maior responsabilização da sociedade pela pacificação social, dando maior cunho democrático às instituições sociais, atuando como

baixo, totalmente a revelia dos sentimentos populares, por classes de grandes senhores 'quase feudais', de intelectualóides manobradores e cegos e de militares traidores. É opção do sistema, que vê nisso forma de manutenção do status quo. Justiça inoperante, mesmo que, para isso, paguem até seus próprios protegidos. O processo judicial é formalista, caro lento e ineficaz." (FIÚZA, 1995, p. 36-7).

${ }^{12}$ Kazuo Watanabe alerta que a cultura brasileira é muito dependente de autoridade não havendo organização da sociedade, individualista, em um trabalho coletivo e que os meios alternativos de solução de conflitos necessitam de um terreno fértil, de uma mentalidade receptiva para prosperar. Comparando a sociedade ocidental com uma oriental, aponta que esta tem muito mais espírito coletivo do que aquela. E entre o Brasil e os Estados Unidos, aponta a existência de mais espírito coletivo, neste, talvez pela forma de viver, por força da religião ou da liderança comunitária. Aponta que, no Brasil, "para lançarmos uma semente tão generosa como a mediação", precisaríamos preparar o terreno e as "nossas academias para que os futuros profissionais de Direito entrem no mundo prático com uma mentalidade mais compromissada com a sua atuação social.” (WATANABE, 2004, p. 44, 49). 
mecanismo de incentivo à comunicação, à educação e ao aprimoramento de uma cultura para a paz, integrando os diversos grupos e as diversidades desses grupos sociais através da utilização de seus potenciais de criação, comunicação, motivação, aprimoramento e crescimento individual e coletivo, trazendo-os para uma posição de inclusão democrática na administração dos conflitos e da justiça e na condução das questões sociais. ${ }^{13}$

Além disso, em atendimento às necessidades de pacificação, inclusão social e acesso à justiça, deve estar alicerçado no:

a) respeito à dignidade humana;

b) no exercício da cidadania;

c) na melhoria das relações interpessoais e na conseqüente melhoria da qualidade de vida, de harmonia, de desenvolvimento da paz social e das relações sociais (comerciais, de consumo, de família, de sucessão, penal, escolares etc.) incidindo em todo complexo universo das relações humanas; no conhecimento e implantação da paz como instrumento de educação continuada ou de solução educativa dos conflitos;

d) e contribuindo para o exercício e promoção dos direitos, como instrumento de inclusão social com o resgate da auto-estima dos indivíduos.

\subsection{Contornos}

Em decorrência dos diversos campos do conhecimento que formam a base e as características dessa modalidade, a lei deve, no que diz respeito à sua introdução efetiva no sistema, delinear o perfil do instituto:

a) assinalando os padrões de procedimento a serem respeitados;

b) designando seus princípios informadores, de forma a assegurar o respeito aos interesses de cada um, a liberdade e a autonomia das partes e a garantir a flexibilidade na opção pelo mecanismo, harmonizando os interesses dos participantes com base na boa-fé, no equilíbrio e na igualdade dos mediados;

${ }^{13}$ Jean-François Six entende que ainda que haja a proliferação dos instrumentos de comunicação, religando e atravessando o planeta, é sabido que esta, no quotidiano das cidades, é falha (carência de escuta, de compreensão, de diálogo) com a tendência do indivíduo se atomizar, se fechar em seu casulo, desintegrando o tecido social. A mediação, por sua própria característica, destinada a criar ou restaurar laços, permite uma melhor atuação nesse âmbito, através da presença ativa de um terceiro, independente e sem poder, ela pode atuar na consolidação desse tecido social, não substituindo as instituições e as associações, mas propondo uma abordagem complementar. (SIX, 2001, p. 175-6). 
c) definindo os princípios éticos norteadores da atividade do mediador e dos mediados, proporcionando maior segurança aos procedimentos;

d) detalhando a formação dos profissionais interventores, respeitadas as diferenças entre os tipos de mediação a serem desenvolvidos, com conteúdos, atividades, critérios e exigências adequados;

e) estabelecendo a segurança dos acordos alcançados nos processos mediacionais, atribuindo-lhes força executiva e/ou facilitando sua homologação, nos casos em que for necessária, e/ou facilitando sua execução;

f) possibilitando ao julgador o incentivo à utilização da mediação endoprocessual ou judicial, através de analise do caso e encaminhamento das partes.

\subsection{Ação}

Para alcançar e implantar as particularidades traçadas para o instituto devem ser estabelecidas modalidades de execução das ações estatais e comunitárias que contribuam paro desenvolvimento do mecanismo e para a consolidação de seus objetivos, bem como da democracia, do estado de direito e dos direitos fundamentais. E, nesse propósito, a política deve determinar a ação governamental no sentido de:

a) promover e apoiar a educação e a formação para a mediação, em especial com a inclusão pelos órgãos competentes de disciplinas e projetos específicas nos currículos mínimos dos cursos superiores, no ensino fundamental e médio;

b) divulgar, disseminar, incentivar e desenvolver o uso da mediação como forma de pacificação, transformação social e acesso à justiça;

c) estimular, apoiar e fomentar a estrutura, as ações e o uso da mediação comunitária, institucional e judicial abrangendo a implantação e utilização da mediação comunitária, através de organizações cidadãs ligadas às comunidades, estimulando o uso do mecanismo, o acesso à justiça e proporcionando a educação social e a informação para a paz, inclusive, com incentivo financeiro, e a a criação, fomento e desenvolvimento de órgãos institucionais públicos e privados de mediação, em especial melhorando e racionalizando o uso dos serviços públicos, mormente judiciais, com a criação de órgão institucional, ligado ao Judiciário, para a implantação e utilização da mediação endoprocessual ou extraprocessual, respeitada a dualidade da organização judiciária de cada ente da Federação;

d) proteger efetivamente as partes e a sociedade, sobretudo com a instituição da fiscalização e acompanhamento do trabalho do mediador e das instituições privadas e comunitárias voltadas à mediação, por meio da 
Mediação - um instrumento de pacificação social: educar para a paz

criação de órgão ou atribuição de competência à instituição para congregar, normatizar e fiscalizar as atividades de mediação e dos profissionais da área.

\subsubsection{Promoção e apoio à educação e à formação para a paz}

Qual a razão de uma formação em mediação?

Com o ensino como instrumento, caminhos são traçados para melhorar o mundo. Como a educação está intimamente ligada aos valores sociais, através dela aprendemos a nos conhecer, trabalhar nossos sentidos, nossos poderes. Não há lei que possa consertar a sociedade, temos que investir na educação como forma de orientação da sociedade.

A atividade pedagógica se estabelece na conformação dos valores sociais a serem alcançados e propagados e na geração e desenvolvimento do conhecimento e, além de elemento essencial para alcançar os objetivos já apontados anteriormente, a resposta pode ser encontrada dentro do próprio objeto da escola - o homem - da razão do ensino em todos os níveis e formas, definidos de acordo com o momento histórico, que aponta como conteúdo central do questionamento desse século o próprio homem dentro da sociedade, pensado através das relações que mantém com os demais membros. A escola, neste intuito, pode e deve redirecionar seus propósitos passando a construir a história, a personalidade social e a esclarecer os contornos desse problema - a definição e explicação do homem como membro participativo e ativo de sua sociedade.

Assim, a inclusão da mediação no ambiente escolar, no processo educativo pode proporcionar o redimensionamento do homem, da sociedade e da escola, atuando de forma a:

a) valorizar a história de todos na construção de suas vidas;

b) privilegiar o conhecimento da totalidade de relações nas quais o homem se envolve, independentemente de localização geográfica - internacional, interna ou de vizinhança - valorizando o ser mundializado;

c) firmar a noção de sociedade como aquela constituída pelo conjunto de homens que, sob as mesmas condições de vida, participam de todos os problemas de todos os homens, levando à percepção de que somos capazes de construir uma sociedade igualitária e pacífica através do conjunto de ações de todos;

d) incentivar a comunicação e a expressão do homem em todas as suas formas;

e) avaliar o processo de participação de todos nos problemas sociais, de forma a analisar a utilização do senso comum no encaminhamento de respostas; 
f) estimular a formação do homem que busca entender e agir coerentemente com a sociedade;

g) estudar, de maneira crítica, a construção moderna do mundo, bem como os processos de humanização para incentivar as formas não-coercitivas e autônomas de resoluções de conflito.

E, nesse contexto, não podemos falar em formação ou transformação da sociedade sem pensarmos em processos educativos, se não pudermos, através das instituições relacionadas ao ensino, proporcionar as condições para que as relações humanistas e cidadãs floresçam e se desenvolvam. Para tanto se faz recomendável a promoção do ensino, informação e formação do conhecimento e da técnica de cooperação e tolerância - mediação -, em todas as idades ${ }^{14}$, como disciplina dos currículos escolares ou através de projetos de cidadania, com base teórica, prática e com estágios de formação ou, ainda, com a produção de trabalhos voltados ao incentivo das técnicas e divulgação destas ou com a formação de grupos de direitos humanos que abordem todos os temas correlatos.

A inserção nos níveis básico e médio traz a possibilidade de auxiliar no desenvolvimento da personalidade, aptidões e capacidades de nossas crianças e adolescentes voltadas para uma cultura de respeito ao outro, aos direitos humanos $\mathrm{e}$ às liberdades fundamentais, aos pais, à sociedade, à sua cultura e às diversidades culturais, preparando-os para assumirem uma vida responsável em sociedade com espírito de tolerância, compreensão, igualdade, amizade e paz entre os povos, entre os grupos étnicos e as diversidades existentes ${ }^{15}$.

Nos cursos superiores com sua inserção no preparo dos profissionais ligados principalmente às áreas de direito, que vão compor o judiciário, de administração, economia, psicologia, que mais utilizam a negociação em suas rotinas diárias, mas que não possuem formação, nem na graduação nem na pós-graduação, para a utilização desta técnica de comunicação, que exige um amplo espectro de conhecimentos envolvendo circunstâncias de diversas áreas (jurídica, psicológica, sociológica, dentre outras) ${ }^{16}$.

${ }^{14}$ A mediação pode ser ensinada e explicada de diferentes formas, desde as negociações internacionais até às crianças em início de idade escolar. Os princípios são exatamente os mesmos e o aprendizado na infância será levado para a fase adulta e utilizado para a vida. (MARTINELLI, 2002, p. 37-38).

${ }^{15}$ Com pleno acolhimento do disposto na Constituição brasileira (Artigo 205); na Declaração Universal dos Direitos Humanos Artigo XXVI, 2; na Convenção Internacional sobre a Eliminação de todas as Formas de Discriminação Racial, Artigo $7^{\circ}$ e na Convenção sobre os Direitos da Criança, Artigo 29,I, a,b,c,d. 
Mediação - um instrumento de pacificação social: educar para a paz

Além da introdução e aplicação dos conhecimentos e da técnica de mediação no ensino regular, imprescindível o estabelecimento de treinamentos e programas educacionais que preparem intermediários nas mais diferentes áreas das questões sociais, em abordagens e habilidades relevantes, qualificando-os para a atuação em área específicas das questões sociais.

\subsubsection{Divulgação e disseminação do mecanismo}

A implantação dessa política de pacificação justifica a criação de um departamento de mediação vinculado ao governo federal e a facilitação da alocação de órgãos em nível estadual e municipal voltados à finalidade de divulgação do mecanismo nas relações internas e internacionais por meio de uma atuação de promoção, apoio e disseminação desses serviços nacional e internacionalmente, através dos tribunais internacionais e da estrutura nacional.

Sua atuação poderia ocorrer no sentido de:

a) supervisionar a política de desenvolvimento da mediação e servir de elo de ligação e comunicação entre os poderes públicos envolvidos, órgãos de mediação comunitária e institucional privados, instituições de ensino etc.;

b) formular e implementar a aplicação dos recursos destinados ao incentivo e disseminação do mecanismo;

c) supervisionar e dar suporte técnico ao desenvolvimento e implantação de treinamentos e programas de educação nas técnicas de mediação;

d) promover cursos de formação em conjunto com órgãos públicos, privados e instituições educativas;

e) fomentar o estudo e compilação das técnicas e as normas pertinentes à mediação visando seu aprimoramento e aperfeiçoamento;

f) estimular e auxiliar a formação de sistemas de mediação, treinamento, facilitação e outros relacionados ao fomento das habilidades e capacidades inerentes à administração de conflitos visando a implantação ou desenvolvimento de órgãos de mediação;

${ }^{16}$ Jean-François Six (2001, p. 61) alerta que os juizes, os psicólogos, os trabalhadores sociais, os especialistas e os advogados, profissões binárias, têm os seus trabalhos a fazer e o mediador por sua natureza e por sua função ternária, não pode ser assimilado por nenhuma delas, que devem se manter em seus papéis. E, continuando, alega ser proveitoso aos advogados a formação em mediação; não pelo 'fazer', mas para saber que se trata de atividades diferentes, contrariamente aos que pretendem 'fazer mediação todos os dias'. 
g) dar suporte financeiro para o estabelecimento, alargamento e operacionalização de iniciativas públicas e privadas na esfera da solução alternativa de conflitos em especial a mediação;

h) divulgar e supervisionar o desenvolvimento de tecnologias de mediação;

i) informar a sociedade sobre sua atuação e sobre centros de mediação no Brasil e no mundo;

j) incentivar a formação de escritórios estaduais, regionais, locais e/ou setoriais, através de convênios, para atuar em conjunto com o departamento na facilitação e incentivo do uso do mecanismo, de forma mais pontual e direcionada aos conflitos e questões das comunidades;

k) fomentar e incentivar a iniciativa comunitária mobilizando os recursos existentes, financeiros, humanos e tecnológicos, para a prevenção da violência.

\subsubsection{Conformação da estrutura}

A estrutura a ser acatada deve considerar as diferentes relações sociais a serem albergadas, desde as mais complexas, como as que envolvem questões jurídicas relacionadas a interesses econômicos (como os negócios internacionais e os grandes contratos), passando pelas que independentemente do aspecto financeiro têm relevante valor social (como as relações de família, de trabalho, de sucessão, as relacionadas ao adolescente, à matéria penal, ao consumo), até chegarmos às questões que, embora atinjam a sociedade de forma contundente, acabam ficando à margem da apreciação do direito, mas provocam efeitos multiplicadores nos conflitos e exercem um papel antipedagógico ou do "mau-exemplo" (como as relações de vizinhança, escolares, comunitárias, políticas).

Nesse intuito, a estrutura deve ser desenvolvida conforme a origem e características do conflito, visando proporcionar uma mediação e um mediador mais próximo de seu sentido e de seus aspectos distintivos e, portanto, mais apta a desempenhar sua função, apresentando uma atuação e resultados mais efetivos e albergando os diferentes tipos de litígios, de acordo com suas necessidades específicas.

Com essa característica de atuação podemos destacar o modelo que utiliza a adoção de órgãos comunitários ou cidadãos e institucionais, cujos procedimentos podem ser: extrajudiciais - realizados à margem dos tribunais, geralmente por iniciativa das partes e por intermédio de centros ou institutos de mediação privados ou até mesmo relacionados ao Estado (Judiciário ou Executivo); e judiciais - praticadas por autorização ou determinação legal nas questões levadas 
à apreciação do Judiciário, após avaliação prévia da viabilidade de utilização do mecanismo, mas sempre por vontade das partes envolvidas e, podendo desenvolver-se em setores especializados por matérias como trabalho, família, adolescentes, penal, consumo etc.

A mediação comunitária tem destaque nas comunidades atuais, em virtude das grandes transformações sociais que levaram à desagregação e alienação dos indivíduos em relação aos demais, a presença do outro como interventor na solução das desavenças diárias passou a quase não existir.

Atualmente, ainda que haja um resgate das relações familiares, o quadro que se apresenta é de ampliação das relações comunitárias, nas quais os vizinhos e amigos, expandindo as inter-relações com valores diferentes, são obrigados a assumir um papel importante de auxiliares nas dificuldades do dia a dia, e de mediadores nos conflitos cotidianos, evitando que se tornem crônicos, que derivem para a violência ou até mesmo que abalem ou desintegrem a, atualmente frágil, estrutura familiar, com conseqüências inevitáveis no âmbito social, fatos que têm se verificado com freqüência. Diante da importância dessas relações, como desenvolver e motivar esse movimento tão essencial para o aprimoramento, crescimento ético e cidadão e para a paz social?

A mediação comunitária tem se apresentado como alternativa viável de atuação e que garante grande retorno ${ }^{17}$, pois os órgãos comunitários são direcionados à propagação da cidadania e da dignidade humana; proporcionam maior inclusão social e política, maior pacificação social através da prevenção, solução e pacificação de conflitos. Seus procedimentos são extrajudiciais, prévios e facultativos e caracterizam-se por serem o mais informal possível; utilizarem voluntários representantes e/ou conhecedores das diferentes necessidades do ambiente em que está inserida a comunidade; serem procedidos, em geral, por iniciativa dos próprios membros; pela gratuidade da intervenção - com o escopo de permitir o acesso ao direito a todos --; e pela promoção do inter-relacionamento e da colaboração. E, através destas particularidades, possibilitam estimular a responsabilidade civil e a consciência de direitos, viabilizar a intervenção antecipada - evitando o aprofundamento do conflito - e ser uma alternativa ao modelo tradicional, auxiliando o sistema e aperfeiçoando a solução de litígios.

${ }^{17}$ Para Lília Maia de Morais Sales a intervenção comunitária destina-sea criar laços e fortalecer o sentimento de cidadania e de participação social, desenvolvendo valores, conhecimentos, crenças, atitudes e comportamentos conducentes ao fortalecimento de uma cultura política-democrática e uma cultura de paz. (SALES, 2004, p. 134135). 
Podem ser incentivados e promovidos, desde que sempre presente a participação e a vontade efetiva da comunidade a ser atendida, por meio de convênios com entidades privadas sem fins lucrativos, entes públicos governamentais e/ou entidades educacionais e através de programas e instituições, que são a espinha dorsal da atuação do mediador comunitário. Exemplificativamente:

a) realização de convênios entre as instituições de ensino superior - públicos ou privadas - e/ou os tribunais e/ou associações para a formação de balcões de cidadania com orientação jurídica e formação de mediadores comunitários para trabalhar na solução das questões da comunidade, principalmente naquelas em que há uma litigiosidade maior, decorrente de questões econômicas e sociais, proporcionando maior acesso ao Direito e à justiça, com a solução e prevenção dos conflitos, e permitindo a pacificação e a inclusão social, através do sentido de pertença e de atuação efetiva da comunidade e do estado em face dos problemas enfrentados ${ }^{18}$;

b) promoção de instituições e centros de justiça comunitários com a disponibilização de verbas públicas e assessoria às comunidades para a concretização das associaçães e integração dos moradores na realização de mediação comunitária com serviços de mediação gratuita ou de baixo custo, abrangendo as áreas de maior necessidade e interesse de cada comunidade. ${ }^{19}$;

${ }^{18}$ A exposição de motivos da criação das Câmaras de Justiça e de Direito Francesas, mostra uma realidade universal e atual: “...o desenvolvimento rápido das grandes cidades provocou o aparecimento de periferias e de zonas urbanas onde as populações vivem em situação de marginalidade e se encontram incapacitadas no que diz respeito à aplicação dos recursos de regulação da vida coletiva. A ação dos poderes públicos e dos responsáveis locais deve se desenvolver neste setor com o objetivo de restaurar o direito, procurando a adesão das pessoas envolvidas e assegurando a articulação dos diferentes programas de luta contra a exclusão e a insegurança. [...] A mediação comunitária torna-se a possibilidade do acesso material à justiça para os indivíduos excluídos da sociedade. Representa não só a possibilidade do acesso à Justiça por aqueles que jamais a alcançariam pelos meios tradicionais, como a inclusão social deles, já que lhes atribui a responsabilidade de decidir o conflito (em pé de igualdade). O sentimento de inclusão, não de abandono, cria laços entre os indivíduos que os fazem mais forte, evitando conflitos e conscientizando-os para o bem-estar social.”. (SALES, 2004, p. 159).

${ }^{19}$ A associação teria uma "tarefa de inventividade: encontrar passarelas entre uns e outros, abrir caminhos e, assim, prevenir os estancamentos e os conflitos [...] impulsionar todos os habitantes a tornarem-se verdadeiros mediadores onde estão, no quotidiano.” (SIX, 2001, p. 174-175). 
Mediação - um instrumento de pacificação social: educar para a paz

c) formação de mediadores por meio de cursos de treinamento e programas de preparo e qualificação nas abordagens, técnicas e habilidades relevantes à área de atuação, conforme o perfil da comunidade em que se inserir o interventor.

A mediação institucional, verificada perante órgãos institucionais, assim entendidos por surgirem e estarem relacionados às estruturas de poder estabelecido, é realizada por profissionais que devem apresentar um grau de qualificação compatível com a complexidade dos problemas a serem enfrentados. Pode estar presente nos órgãos do poder político (Judiciário, Executivo e/ou Legislativo) ou estar ligada a instituições privadas, a segmentos da sociedade (econômico, profissional etc.). Ela se particulariza por se desenvolver com base em normas e diretrizes pré-instituídas - institucionalização do mecanismo -, pelo estabelecimento de condições previamente fixadas e pela necessidade de formação e preparo específico do mediador para este fim, e, salvo determinação contrária, pode ser onerosa a atividade do terceiro.

Assim, a atuação do mediador institucional exige uma formação aprofundada, regulamentação e organização próprias, pois, falta à maioria dos profissionais, a quem se quer atribuir a função, conhecimento interdisciplinar com informações sobre postura, psicologia, comportamento, sociologia, que os aproxime da sociedade e dos problemas das partes, conteúdos estes que não são ministrados nas escolas, nas faculdades ou nas pós-graduações, mas que tratam do perfil desejado ao terceiro mediador, fazendo com que tenha os pés no chão e a cabeça nos mediados. Para tanto é necessário que sejam estabelecidos critérios de formação mínima, com prova de habilidade, reciclagem periódica, princípios éticos, princípios condutores que norteiem sua atividade. Além disso, há a questão da existência de entidades "fantasmas" que se denominam com nomes pomposos e que realizam cursos "duvidosos” prometendo formação como mediador sem o menor critério ou fundamentação para tal, aproveitando-se do desconhecimento por parte da sociedade e de vários setores das atividades jurídicas, sociais e empresariais e por falta de conhecimento e de regulamentação da atividade.

Nesse propósito, dentre outras, deveriam ser estabelecidas medidas de:

a) regulamentação da atividade de mediador com a estruturação de conteúdo e carga horária mínimas para os cursos de formação, exigência de estágio e de avaliação das condições para seu exercício;

b) exigência de atualização e reavaliação periódica dos mediadores, pois é essencial que realizem sistematicamente uma reflexão sobre suas ações, que transformem sua prática em um objeto de reflexão, contribuindo para sua formação, pra a construção de seu conhecimento e dos demais 
mediadores, para a elaboração e direcionamento das bases da mediação e para a construção de uma identidade profissional e da qualidade do serviço prestado à comunidade.

Há ainda que considerar-se a complexidade dos conflitos a serem tratados, que tornam necessária a determinação de normas básicas a serem seguidas no procedimento de mediação, relacionadas às advertências às partes, aos documentos a serem firmados, à representação, aos prazos - sem cercear a liberdade e a necessidade do processo de mediação -, às despesas, ao devido processo legal, no que for pertinente etc.

Além destas, apresenta-se também necessário o incentivo e a facilitação do uso do mecanismo dentro e fora dos tribunais com a adoção de medidas como:

a) a atribuição de força aos acordos por meio da outorga de competência complementar para a homologação de acordos provenientes de mediação, quando essenciais ao direito e objeto em discussão;

b) a facilitação do cumprimento dos termos finais através da criação de órgãos com competência para a execução dos acordos de mediação com procedimentos simplificados e diferenciados das decisões judiciais e da simplificação e regulamentação da execução em território brasileiro dos acordos realizados com base em legislação estrangeira, quando necessária;

c) a retirada de óbices legais e inclusive com vantagens tributárias e outros instrumentos que proporcionem maior conveniência e utilidade de seu uso.

Quanto à mediação judicial endoprocessual, poderia, ainda, ser incentivada através da:

a) criação de um órgão ligado ao Judiciário (mediação familiar, penal, sucessória etc.), por convênio ou por manutenção própria, com listas de mediadores cadastrados, a ser renovada periodicamente, com provas de habilidade ou capacidade, podendo ficar impedidos de atuar em outra atividade que não a de mediador, nesse caso, receberiam pagamento de vencimentos mínimos pelo estado;

b) determinação de avaliação das questões levadas ao Judiciário - prévia, criteriosa e exigente, de forma a não permitir processos não mediáveis, expedientes protelatórios no cumprimento das decisões judiciais e denegação da justiça, ao invés de sua realização - a ser procedida pelos juízes ou membros do Ministério Público, treinados para este fim, propondo às partes por notificação a adoção do procedimento, antes do prosseguimento da ação;

c) possibilidade de uma audiência de esclarecimento sobre a utilização do mecanismo sua sistemática e implicações, permitindo às partes conhecer 
Mediação - um instrumento de pacificação social: educar para a paz

e optar livremente por sua utilização; d) faculdade de utilização a qualquer tempo e estado do processo.

\subsubsection{Proteção da sociedade}

A proposta visa proteger as partes, a sociedade, o cidadão e os próprios mediadores da atuação desvirtuada das pseudoinstituições de mediação e dos pseudomediadores através da criação ou atribuição de competência a órgão específico de congregação, acompanhamento e fiscalização da atividade de mediador e das instituições privadas e comunitárias.

A entidade a ser formada não pretende cercear a atuação, formação ou estabelecimento da atividade, mas apoiar, dar suporte, nortear e permitir maior transparência e credibilidade a uma atividade de tamanha importância nas questões sociais, no acesso à justiça, no estabelecimento da participação democrática e na transformação social. Sua atuação se daria com:

a) a congregação e reunião das instituições ligadas à mediação e dos mediadores;

b) a avaliação de conhecimentos e atuação dos mediadores e da idoneidade e representatividade social para a execução da atividade proposta pelas instituições;

c) o estabelecimento de código de ética para os mediadores e fiscalização de sua aplicação;

d) a discussão das questões ligadas a atividade, apreendendo suas necessidades e promovendo o intercâmbio das iniciativas, inclusive de outros estados;

e) a facilitação da cooperação entre os poderes públicos, as instituições de mediação e os mediadores;

f) o estabelecimento de relação entre os órgãos similares existentes em outros estados da federação e outros países.

\subsection{Incentivo a áreas de atuação da mediação para expansão do mecanismo}

Dentre os campos possíveis de atuação destacamos alguns nos quais o uso da mediação tem se revelado eficaz e transformador, sem a pretensão de estancar as possibilidades de utilização desta importante e interessante ferramenta de ação nas questões e conflitos da sociedade, mas de sugerir ações para ampliar e fomentar as áreas de aplicação da técnica e de modificações legislativas específicas, se necessárias, para que possam albergar, instituir ou incentivar o uso do mecanismo.

A mediação escolar, considerada uma maneira de educar, é desenvolvida a nível mundial, através de programas, e sua utilização tem produzido benefícios 
na administração dos conflitos, melhora o clima escolar e fomenta a formação integral do aluno, preservando as relações entre os atores institucionais e evitando a violência atua na sua diminuição, na qualidade de ensino e no desenvolvimento da aprendizagem escolar, possibilitando a informação, a educação e a formação para a paz e para o diálogo, incentivando a participação na comunidade e a percepção social, ou seja, "formar cidadãos responsáveis, protagonistas críticos, criadores e transformadores da sociedade” (ARSÊNIO, 2005).

A mediação familiar ${ }^{20}$ é um dos campos mais frutíferos para a utilização da mediação, pela diversidade e complexidade de relações que alberga, manifestando os principais problemas que se repetem no seu entorno. A família, célula fundamental da sociedade, comporta ocorrências que, antes de tudo, são eventos pessoais que se expressam por interesses e expectativas relevantes para o direito (evento jurídico), mas também interesses não jurídicos de natureza afetiva, emocional, material, cultural e social. ${ }^{21}$ Nesse âmbito, em que prevalece o direito à intimidade e à vida privada, há mundialmente uma tendência de redemocratização, de se preferir e reconhecer a capacidade e responsabilidade dos envolvidos na resolução consensual dos litígios. Esta opção tem, ainda, a virtude de atuar em um dos grandes entraves dessas questões, a fraca coercibilidade das decisões judiciais, que ocorre não por falta de autoridade, mas de eficácia, que pode ser mais efetiva com a maior proximidade da participação dos envolvidos, principalmente no que concerne ao exercício das responsabilidades parentais, contribuindo na melhoria da justiça de família e possibilitando a adequação, celeridade e eficácia das decisões judiciais. ${ }^{22}$

${ }^{20}$ Sobre mediação familiar ver: Six (2001), Farinha (2004), Groeninga (2001, p. 72 et seq.), Lagastra Neto (2000, 2004), Serra (1999); Martinez I Camps (2001).

${ }^{21}$ Maria Montserrat Martinez I Camps (2001) expõe que escapam ao Direito de Família as peculiaridades das relações familiares, os aplicadores do direito muitas vezes encontrem-se impotentes a sua mutabilidade, envolvimento emocional (provocador de um distanciamento dos interesses ou uma dificuldade de aproximação) e complexidade, cujas questões podem albergar múltiplos pleitos (guarda dos filhos, partilha dos bens, afastamento do cônjuge, pensão alimentícia).

${ }^{22}$ Esse papel relevante, subsidiário e supletivo do estado nas questões familiares é realidade fundamental nessa área do direito, principalmente em atendimento ao disposto no Pacto Internacional dos Direitos Civis e Políticos (Artigo 23, 4) que determina a obrigação dos estados de adotarem medidas para assegurar a igualdade de direitos e obrigações dos cônjuges durante e na dissolução do casamento, assim como as medidas necessárias para assegurar a proteção aos filhos, e Pacto de San José da Costa Rica que traz igual disposição (Artigo 17, 4) acrescentando que a base das 
Mediação - um instrumento de pacificação social: educar para a paz

A mediação sucessória ${ }^{23}$ permite relevar, trabalhar, harmonizar e encontrar soluções criativas para estes conflitos cujos interesses não são resolvidos somente com a aplicação da lei. Sua adequação advêm de sua apropriação à discussão dos diferentes interesses e pontos de tensão envolvidos, que se entrelaçam e produzem reações complexas. Nessas questões, semelhante às relações de família, há a conexão entre múltiplos aspectos (econômicos, sociais, emocionais, jurídicos) que constituem o problema, fazendo com que a atuação, em qualquer de suas perspectivas, tenha reflexos nos demais interesses e interessados, dificultando uma tomada de decisão que não somente ponha fim à lide, mas traga pacificação efetiva, suscitando uma relação nova entre os envolvidos e de respeito mútuo - na qual cada um pode guardar sua identidade e seus reais interesses e aspirações. ${ }^{24}$

A mediação penal pode ser utilizada como instrumento para tornar em uma realidade mais próxima, cotidiana, o crime e a criminalidade, que não se constituem em uma questão distante e isolada, pois ao mesmo tempo em que é um evento na vida do indivíduo que o pratica, têm seu nascedouro na comunidade, com altos custos pessoais e sociais, e que por ela deve ser resolvida (MOLINA; GOMES, 2002). Isto torna necessário a construção de um panorama

medidas deve ser o interesse e conveniência dos filhos; e na Convenção sobre os Direitos da Criança, (Artigo 27, 4) que dispõe sobre a adoção de medidas para assegurar o pagamento da pensão alimentícia por parte dos pais ou de quem seja responsável financeiramente pela criança; e em cumprimento aos preceitos constitucionais estabelecidos: no Artigo 226, parágrafo $8^{\circ}$ que prevê a criação de mecanismos para coibir a violência no âmbito de suas relações; no Artigo 227 que determina à família, à sociedade e ao Estado assegurarem à criança uma vida saudável e fora de qualquer forma de violência e no Artigo 230 que impõe o dever à família, à sociedade e ao Estado de amparar as pessoas idosas, assegurando sua dignidade, bem-estar e direito à vida.

${ }^{23} \mathrm{O}$ projeto de lei n. $4725 / 2004$, abre a possibilidade concreta de uso da mediação privada em sucessão ao delegar ao Tabelião de Notas nos casos de inventário, se todos forem capazes e concordes, proceder ao inventário e à partilha por escritura pública, cujo título será o instrumento hábil para o registro imobiliário.

${ }^{24}$ Marcelo Gobbi (2004) ilustra a dinâmica de um conflito de sucessão com um legado ea dois museus uma pinacoteca heterogênica, em partes iguais, sem especificar que obras deveriam ser adjudicadas a qualquer dos legatários. O destino dado a qualquer das pinturas produzirá efeitos sobre cada uma das demais pinturas. Aquele que ficar com uma impressionista, provavelmente perderá o interesse por outros impressionistas e pretenda obras de outras escolas, o que incidirá no outro de maneira simétrica ou complementar, segundo as características das obras que este já possua. 
dos acontecimentos delitivos e uma atuação voltada à ressocialização do infrator e à prevenção do delito, que implica na mobilização solidária de todos os setores da comunidade para o enfrentamento do problema.

Apesar de muitas medidas previstas em nossa legislação penal com o intuito de alcançar este intento ${ }^{25}$, não se tem conseguido alcançar o efeito desejado, por razões várias que denotam a necessidade de ampliação da participação popular na administração da justiça penal, para alcançar a promoção da aplicação de penas mais humanas e comprometidas com a ressocialização do infrator. Nesse contexto, a mediação tem a vocação, penetração e perspectiva de oferecer a condição de dar à definição e à aplicação das penas maior proporcionalidade e proximidade com o caráter e condição da vítima, do infrator e do delito cometido, proporcionando uma justiça reparadora e não retributiva ou punitiva que permita ao transgressor perceber o ser que existe na outra ponta da relação - o ofendido - e a conformação, sintonia e apropriação da pena a ser aplicada, mais pertinente ao infrator e à sua readequação social e mais relevante à vítima, possibilitando uma compreensão do autor do delito isenta do estigma de que todo transgressor é delinqüente e que todo delinqüente é irrecuperável e como oportunidade de enxergá-lo como igual e não como ser diferente e alienígena em nossa sociedade.

Pode ser aplicada, a princípio, nas questões de delitos de menor potencial ofensivo e de ação penal privada ou condicionada a representação, principalmente no que se refere à aplicação das penas alternativas, assim como nas questões relacionadas ao adolescente ${ }^{26}$, como forma de alcançar o previsto na Constituição, em seus Artigos: 227, 228 e 229, que estabelece a responsabilidade da família, da sociedade e do estado no desenvolvimento, educação, amparo e garantia dos direitos fundamentais da criança e do adolescente e no Estatuto da Criança e do Adolescente (Lei n. 8.069/90), que prevê uma justiça reparadora e não retributiva, ou protetiva e não punitiva. O mecanismo permite a compreensão das questões ligadas a adolescência e a atos infracionais, da realidade da criança e do adolescente e de suas especificidades no contexto social e familiar ${ }^{27}$, que precisam ser vistas

${ }^{25}$ Podemos citar: casas de albergados e colônias agrícolas; trabalho comunitário; encaminhamento de ex-detentos a empresas conveniadas; programa de ocupação assistida para adolescentes infratores, prestação de trabalhos comunitários, penas alternativas etc.

${ }^{26}$ Ver: Six (2001), Farinha (2004), Pietrocolla, Sinhoretto e Castro (2000).

27 "A família e a mídia são também os responsáveis diretos por alimentar a delinqüência, na medida em que a organização criminosa substitui o estado, ocupando os espaços deixados pela inércia e corrupção dos governados." (LAGASTRA NETO, 2004). 
Mediação - um instrumento de pacificação social: educar para a paz

considerando-se as peculiaridades desta fase da vida (FRASSETO, 1999, p. 163), possibilitando na aplicação das medidas sócio-educativas o alcances da eficácia esperada.

A mediação de conflitos de propriedade envolve um dos mais antigos institutos jurídicos criados pelo homem, em sua concepção atual de aceitação da imposição de limites e condicionantes ligados ao seu uso apropriado ${ }^{28}$, questão que gera não somente discussões sociais, políticas e doutrinárias, mas também inúmeros conflitos em torno de sua utilização, regularização e domínio.

No campo ${ }^{29}$, apesar do consenso aparente no que se refere à necessidade e importância da reforma agrária, com o passar dos anos muito pouco foi ou tem sido alterado na estrutura fundiária no Brasil, ocasionando a eclosão de movimentos sociais. Mesmo com a ciência da gravidade e urgência nas ações a serem implementadas, o pouco realizado demonstra quase nenhuma vontade política em agir, gerando o aprofundamento de uma situação que põe em risco uma das atividades econômicas mais importantes em nosso estado, a produção agrária. Esses conflitos vão muito além das relações interindividuais, neles a terra significa não só um patrimônio, mas tem formas e razões de reivindicação distintos, sem se tratar de discussão semântica, mas política ou de interpretação da extensão de princípio legal. Para os "invadidos” há a lesão em seu direito à propriedade (Artigo 5 $5^{\circ}$ XXII CF), para os "ocupantes” há o direito de ocupação pela improdutividade das terras (Artigo $5^{\circ}$, XXIII CF). Nesse conjunto, propor o diálogo e estar disposto a dialogar é essencial para que se possa convergir interesses múltiplos e divergentes através de propostas de consenso, contexto em que se insere a mediação de conflitos, proporcionando a ampliação das perspectivas e a configuração de ações a serem desenvolvidas.

No setor urbano a situação não é menos preocupante, principalmente, em decorrência do êxodo rural que iniciado nos anos 60 (sessenta), que ocasionou o surgimento da propriedade informal, geralmente decorrente de loteamentos

${ }^{28}$ Reconhecida e amparada em nosso sistema, há o estabelecimento de sua garantia (Artigo $5^{\circ}$, XXII - seu aspecto privado) por um lado e por outro há o condicionamento ao bem geral da sociedade, sua função social (Artigo $5^{\circ}$, XXIII - caráter público), pela qual seu uso deve contribuir para com o sistema econômico (Artigo 170, II e III) favorecendo o bem comum.

${ }^{29}$ As atividades de mediação desenvolvidas pelo ITESP alcançaram resultados na pacificação e prevenção de conflitos e na pacificação e inclusão social demonstrando a viabilidade e importância da extensão dessa experiência, como parâmetro para a tratativa da questão fundiária no Brasil. (ANDRADE; PEREIRA; ANDRADE, 2000, p. xiii). 
clandestinos e invasões urbanas, cujo caráter retira de seu titular direitos e garantias que lhe asseguram suas prerrogativas em relação ao bem. Estas situações revelam um Brasil em que as imensas dissonâncias econômicas e sociais e a ineficiência nas políticas habitacionais, em especial para a população mais carente, aliada aos fatores econômicos, como desemprego e baixos salários, e sociais, como o desconhecimento da lei e analfabetismo, tem estabelecido situações paralelas ao direito, deixando os indivíduos à margem de seu abrigo. Estas condições acarretam um estado conflituoso em núcleos habitacionais sem as mínimas condições de saúde e higiene e com as mais diferentes necessidades, gerando os mais variados tipos de conflitos entre os moradores, nas circunvizinhanças e com as autoridades públicas, tanto pela irregularidade da propriedade quanto pela precariedade da situação instalada, uma ocasionada em grande parte pela outra.

Apesar das diferenças entre as realidades agrária e urbana, o panorama dos conflitos é semelhante e, "mutatis mutantis", a aplicação da mediação a estas pendências poderia oferecer a possibilidade de estabelecimento de ações políticas e urbanísticas mais próximas das necessidades e mais adequadas às realidades sociais em questão.

A mediação empresarial, tomando como exemplo o contexto internacional, em que sua aplicação, de modo consistente e dinâmico, tem facilitado o desenvolvimento da lex mercatória, pode ser utilizada como fator de incremento à relações negociais internas e regionais permitindo, ao contrário dos processos adjudicativos, escapar ao critério de certo e errado para uma visão mais dinâmica, transformadora, interativa e criativa do conflito e da relação negocial, harmonizando e acomodando os verdadeiros interesses das partes, sem desacreditar o Judiciário, sua força e presença, essenciais à lei e ordem, mas sintonizando estas relações em um mundo extremamente competitivo, em que "tempo é dinheiro" (PRATES, 2004). É ao lado da arbitragem, o melhor método de solução de controvérsias para essas relações, por motivos como os diminutos óbices legais (predomínio da autonomia da vontade) e o caráter de continuidade e interdependência entre os interesses e/ou pontos de tensão das relações, além de suas inúmeras vantagens como simplicidade e rapidez do procedimento, confiabilidade e especialidade dos interventores, economicidade e eficácia das soluções, que nos tribunais demandam anos para serem decididas.

Dentre as muitas áreas relacionadas ao setor empresarial, além da internacional, poderíamos destacar as relações contratuais, as questões de empresas em dificuldades, principalmente as de pequeno e médio porte, nas quais a mediação pode viabilizar uma alternativa ao processo judicial de concordata e falência, 
Mediação - um instrumento de pacificação social: educar para a paz

permitindo, através de uma atuação negociada fora dos tribunais, a potencialização de sua recuperação, evitando os prejuízos sociais e econômicos de seu fechamento ${ }^{30}$, a gestão de conflitos societários e de processos de fusão e incorporação, cujo êxito depende, em grande parte, da colaboração espontânea e informal, pois os envolvidos continuarão a se relacionar após o término do litígio, seja qual for ele.

A mediação de consumo (ROCHA, 2003, p. 33-48) vem ao encontro da previsão das ações para a implantação da política consumeirista que dispõe sobre a educação e a informação para o consumo e sobre o uso de meios alternativos para a solução dos conflitos (Art. 4, IV e V do CDC). A mediação através de sua capacidade de educar atitudes, possibilita uma mudança comportamental, a formação de habilidades e capacidades para impedir ou diminuir a reincidência dos conflitos, proporcionando o alcance da 'maturidade' dessas relações através de uma 'solução educativa'. O que significa alcançar "o objetivo de propiciar a não repetição do conflito, mas utilizá-lo como um ponto de partida para a releitura da situação” (ROCHA, 2003, p. 41-3), não só do momento, mas para o cotidiano.

A mediação pública refere-se à sua utilização pelo estado, campo em que muito ainda precisa ser feito e no qual são necessárias inúmeras mudanças desde o aspecto cultural, doutrinário e ideológico até o político e legal. Apesar de já existir um movimento tímido ${ }^{31}$, o uso desse mecanismo exige ${ }^{32}$ uma mudança cultural na construção de uma democracia com maior participação cidadã na administração da justiça; que o estado aceite, promova e incentive os meios alternativos de resolução de conflitos, enquanto formas céleres, informais, econômicas e justas de administração e realização da justiça, assumindo e afirmando, através de modificação legislativa; que o estado proponha e aceite ativamente esses instrumentos nas suas relações para a superação dos conflitos em que ele mesmo seja parte; que o estado determine, no contexto da negociação de seus contratos a convenção de cláusulas que privilegiem esses mecanismos,

${ }^{30}$ Experiência semelhante, através da conciliação em Portugal tem desenhando um bom panorama do aproveitamento desta opção. (SILVA, 2002, p. 214-5).

${ }^{31}$ Como nos acordos internacionais e em iniciativas legais como a Lei das parcerias público-privadas, que admite a utilização da arbitragem nos conflitos decorrentes dos contratos firmados, têm-se perdido a oportunidade de estender a previsão para o uso da mediação, mais eficaz na administração de litígios desta natureza.

${ }^{32}$ Ver: Resolução do Conselho de Ministros no. 175/2002. Disponível em: <http:// www.oa.pt/>. 
nos termos da lei e que, no desenvolvimento das suas atribuições, o estado e outras pessoas de direito público que integram a administração direta e indireta proponham e adotem soluções concretas de mediação e de outras vias como modalidades preventivas em seus litígios (MARTINS, 2003, p. 49-62).

\section{CONCLUSÃO}

A partir das células principais de nossas sociedades, partindo das questões familiares, da formação escolar, da atuação comunitária, da participação dos núcleos religiosos, até chegarmos ao Estado e às grandes questões internacionais, é necessário que se implante e modifique a visão de como enfrentar os problemas que fazem parte de nossos cotidianos. Estes não existem isoladamente, fazem parte da intersubjetividade, mas serão encarados de forma positiva ou negativa, construtiva ou destrutiva das relações, conforme possamos assimilar individualmente novos paradigmas de atuação, novos valores sociais, novos conceitos de paz. Ou seja, é necessário educar para a paz através da implantação de uma cultura de atuação política e social de paz, por meio de uma política voltada para a paz.

\section{REFERÊNCIAS}

ANDRADE, Tânia; PEREIRA, Carlos Alberto Claro; ANDRADE, Márcia Regina de Oliveira. Mediação no campo: estratégias de ação em situação de conflito fundiário. 2. ed. São paulo: ITESP, 2000.

ARSÊNIO, Julieta. Resolução alternativa de disputa no âmbito escolar. Disponível em: 〈http://www.pailegal.net>. Acesso em: 6 jan. 2005.

BACELLAR, Roberto Portugal. A mediação no contexto dos modelos consensuais de resolução de conflitos, Revista de Processo, São Paulo, ano 24, n. 95, p. 122134, jul./set. 1999.

BARBOSA, Águida Arruda. Mediação familiar: uma nova mentalidade em direito de família. Revista de Doutrina e Jurisprudência, n. 58, p. 59-64, set./dez. 1998.

BARBOSA MOREIRA, José Carlos. A função social do processo civil moderno e o papel do juiz e das partes na direção e na instrução do processo. Revista de Processo, São Paulo, ano 10, n. 37, p. 140-150, jan./mar. 2000.

BARRETO, Cunha. Repertório de jurisprudência do Código Civil. São Paulo: Max Limonad, 1955. Vercingetorix de Castro Garms, v. 1, n. 71.

BRITTO, Manoel F. Anestesia social. Disponível em: 〈http://www.aol.com.br〉.. Acesso em: 6 set. 2004. 
CONVENÇÃO Internacional sobre a Eliminação de todas as Formas de Discriminação Racial (1968). Disponível em: <http://www.mj.gov.br/sedh/ct/ legis_intern/conv_int_eliminacao_disc_racial.htm>. Acesso em: 7 abr. 2004.

CONVENÇÃO sobre os Direitos da Criança. Disponível em: <http:// www.mj.gov.br/sedh/dca/convdir.htm>. Acesso em: 7 abr. 2004.

DECLARAÇÃO Universal dos Direitos Humanos. Disponível em: <http:// www.mj.gov.br/sedh/ct/legis_intern/ddh_bib_inter_universal.htm>. Acesso em: 7 abr. 2004.

DIAS, José Carlos de Mello. Mediador: uma experiência profissional. In: DELGADO, José et al. Mediação: um projeto inovador. Brasília: Conselho da Justiça Federal, Centro de Estudos Judiciários, 2003. (Série Cadernos do CEJ; v. 22).

FARINHA, António. Mediação e justiça de família e menores. Disponível em <http://www.oa.pt/>. Acesso em: 6 jul. 2004.

FIÚZA, Cezar. Teoria geral da arbitragem. Belo Horizonte: Del Rey, 1995.

FRASSETO, Flávio Américo. Esboço de um roteiro para aplicação das medidas sócio-educativas. Revista Brasileira de Ciências Criminais, v. 7, n. 26, p. 159195, abr./jun. 1999.

GOBBI, Marcelo. La mediación como método apropriado para la gestion de conflictos societarios. Disponível em: 〈http://www.camarbra.com.br/>. Acesso em: 23 fev. 2004.

GROENINGA, Giselle. Mediação e direito de família: uma parceria necessária. Revista do Advogado, São Paulo, n. 62, p. 72-83, mar. 2001.

LAGASTRA NETO, Caetano. Direito de família - a família brasileira no final do século XX, São Paulo: Malheiros, 2000.

LAGASTRA NETO, Caetano. Mediação e direito de família. Disponível em: <http://www.BuscaLegis.ccj.ufsc.br/>. Acesso em: 18 ago. 2004.

MARTINELLI, Dante Pinheiro. Negociação empresarial: enfoque sistêmico e visão estratégica. Barueri: Manole, 2002.

MARTINEZ I CAMPS, Maria Montserrat. La aplicación de la mediación familiar en el derecho de familia. Âmbito Jurídico, ago. 2001. Disponível em: <http:// www.ambito-juridico.com.br/aj/>. Acesso em: 18 ago. 2004. 
MARTINS, Dayse Braga. A mediação no processo de democratização do Estado, In: SALES, Lilia Maia de Morais (Org.). Estudos sobre a mediação e a arbitragem. Rio de Janeiro: ABC Editora, 2003.

MATIAS, Maria Judite. Julgados de Paz versos centros de arbitragem estruturas de mediação de consumo: conflito ou convergência? Disponível em: <http:// www.oa.pt/>. Acesso em: 23 fev. 2003.

MOLINA, Antonio Garcia-Pablos de; GOMES, Luiz Flávio. Criminologia: introdução a seus fundamentos teóricos : introdução às bases criminológicas da Lei 9.099/95, lei dos juizados especiais criminais. 4. ed. São Paulo: Editora Revista dos Tribunais, 2002.

PIETROCOLLA, Luci Gatti, SINHORETTO, Jacqueline; CASTRO, Rosa. $O$ Judiciário e a comunidade: prós e contras das medidas sócio-educativas em meio aberto. São Paulo: IBCRIM, 2000.

PRATES, Odonir Barboza. A arbitragem começa a ganhar espaço na solução de conflitos. Disponível em: 〈http://www.espacovital.com.br/>. Acesso em: 25 nov. 2004.

ROCHA, Amélia Soares. A mediação e o direito do consumidor. In: SALES, Lilia Maia de Morais (Org.). Estudos sobre a mediação e a arbitragem. Rio de Janeiro: ABC Editora, 2003.

SALES, Lília Maia de Morais. A mediação de conflitos e a pacificação social. In: Editora, 2003.

. (Org.). Estudos sobre a mediação e a arbitragem. Rio de Janeiro: ABC - Justiça e mediação de conflitos. Belo Horizonte: Del Rey, 2004.

SERPA, Maria de Nazareth. Mediação de família. Belo Horizonte: Del Rey, 1999.

SILVA, Carlos Manuel Ferreira da. Arbitragem e conciliação. Presente e futuro: a situação em Portugal. Revista de Processo, São Paulo, ano 27, n. 107, p. 204, jul./set. 2002.

SIX, Jean-François, Dinâmica da mediação. Tradução Águida Arruda Barbosa, Eliana Riberti Nazareth, Gisele Groenings. Belo Horizonte: Del Rey, 2001.

URY, William. Chegando à paz: resolvendo conflitos em casa, no trabalho e no dia-a-dia. Tradução Jussara Simões. Rio de Janeiro: Campus. 2000.

WATANABE, Kazuo. Modalidade de mediação. In: DELGADO, José et al. Mediação: um projeto inovador. Brasília: Conselho da Justiça Federal, Centro de Estudos Judiciários, 2003. (Série Cadernos do CEJ; v. 22). 